\title{
THE ROLE OF ECHO DURATION IN ACOUSTIC SEABED CLASSIFICATION AND CHARACTERZATION
}

\author{
Ben Biffard ${ }^{1}$, Steve Bloomer ${ }^{1}$, Ross Chapman ${ }^{1}$ and Jon Preston ${ }^{2}$ \\ ${ }^{1}$ Canadian Marine Acoustic Remote Sensing Facility (C-MARS), School of Earth and Ocean Science, University of Victoria, \\ Victoria, BC Canada, V8V 3P1 bbiffard@uvic.ca \\ ${ }^{2}$ Quester Tangent Corp., 6582 Bryn Road, Saanichton, BC Canada, V8M 1X6
}

\section{INTRODUCTION}

In this paper, the results of two experiments primarily concerning echo duration are summarized. The aim of the experiments is to improve seabed remote sensing using single-beam echosounders by:

- verifying the ray-trace model of echo duration that is used as the basis to remove the affects of depth from the data prior to analysis for classification

- applying a new technique to remove the affects of seabed slope from the seabed echo data

- demonstrating the application of echo duration data for seabed characterization

Current research effort at C-MARS is to develop new and improved seabed classification methods based on the Quester Tangent Corp. method applied in the QTC IMPACT $^{\text {TM }}$ software. Seabed classification segments the seabed into areas of similar acoustic character based on statistics. Further, direct seabed characterization is to be explored. To do this, the physics of echosounding are paramount. In general, echoes from the seabed are composed of three types of acoustic response: reflection, volume backscattering and surficial backscattering. The shape of the echo is largely determined by the total backscatter strength as a function of angle of incidence that increases from nadir as the transmit pulse spreads along the seabed. The echo time series from mud, sand, gravel, and rock seabeds differ in echo attributes that may be called shape, overall duration and relative amplitude. The QTC IMPACT seabed classification method is primarily based on measures that respond to the echo shape.

Deeper echoes are stretched out in time due a slower rate of increase of the angle of incidence relative to echoes from shallower water. This depth dependence has to be compensated so that the classification maps are of seabed types, not maps of bathymetry. All non-seabed influences on the echo must also be held constant or compensated for; this topic is explored further in Biffard et. al., 2007. The biggest source of error in single-beam based seabed classification is seabed slope. It acts in a way very similar to depth - it stretches echoes out in time by making the angle of incidence progress slower. It also changes the angle of incidence as well; at slopes greater than the $1 / 2$ beam width the seabed normal ray is lost severely reducing the coherent reflection from the seabed which changes the echo shape.
The duration of a seabed echo can be modeled with some simple ray tracing, leading to the following: $E_{d}=\frac{2}{c} d \sec \left(\phi+\frac{\theta}{2}\right)+\tau+\frac{2}{c} p+\frac{2}{c} w$

where $d$ is the water depth, c the sound speed, $\Phi$ is the seabed slope, $\theta$ is the beam width, $\tau$ the duration of the transmit pulse, $p$ the depth of penetration in to the seabed defined by $10 / k f$ ( $k$ is the seabed attenuation coefficient in $\mathrm{dB} / \mathrm{m} / \mathrm{kHz}, f$ is the echosounder frequency), $w$ is the height of macro-roughness such as large rocks. This equation is valid for $_{\phi \leq \theta / 2}$. The expression used for the penetration depth is based on $10 \mathrm{~dB}$ extinction and does not consider the reflection coefficient or sediment sound speed. Eq. 1 implies plots of measured echo duration versus depth should be linear. The depth compensation algorithm, named SEL, used in the QTC View series 5 system is based on Eq. 1 assuming nominal values for beamwidth and attenuation.

\section{METHOD}

The experiments required varying the water depth and seabed slope while keeping all other variables fixed. To do this, both depth and slope are simulated in the field by raising and lowering the transducer and by tilting the transducer. This was done at three controlled sites - the sites are flat, homogenous and well characterized by video, grab sample and penetrometer data. These sites are part of our Patricia Bay, BC testbed as detailed in Biffard et. al., 2006.

\section{THE DEPTH EXPERIMENT}

Fig. 1 shows plots of echo duration versus depth. Echo durations were measured using a threshold-based bottom pick and cumulative amplitude 'tail' pick. Linear fits were all are significant, explaining a majority of the variation, and therefore confirming our linear model. The fit produces two parameters: effective beamwidth (slope of the regression line) and effective attenuation (part of the intercept). The effective attenuation values are consistent to those found using the grab samples: 0.6 for sand, 0.4 for gravel, 0.05 for mud. The effective beamwidths were wider than the manufacturer's $-3 \mathrm{~dB}$ beamwidths, but are consistent between the sands and muds. Beamwidths from the gravels are wider because of off-axis surfical backscatter due to high seabed roughness. Depth compensation works by resampling the data to fit within an analysis window. The effective values tune the depth compensation for better 
results, ie the echoes fit in the windows and the variation in echo duration caused by depth is removed.
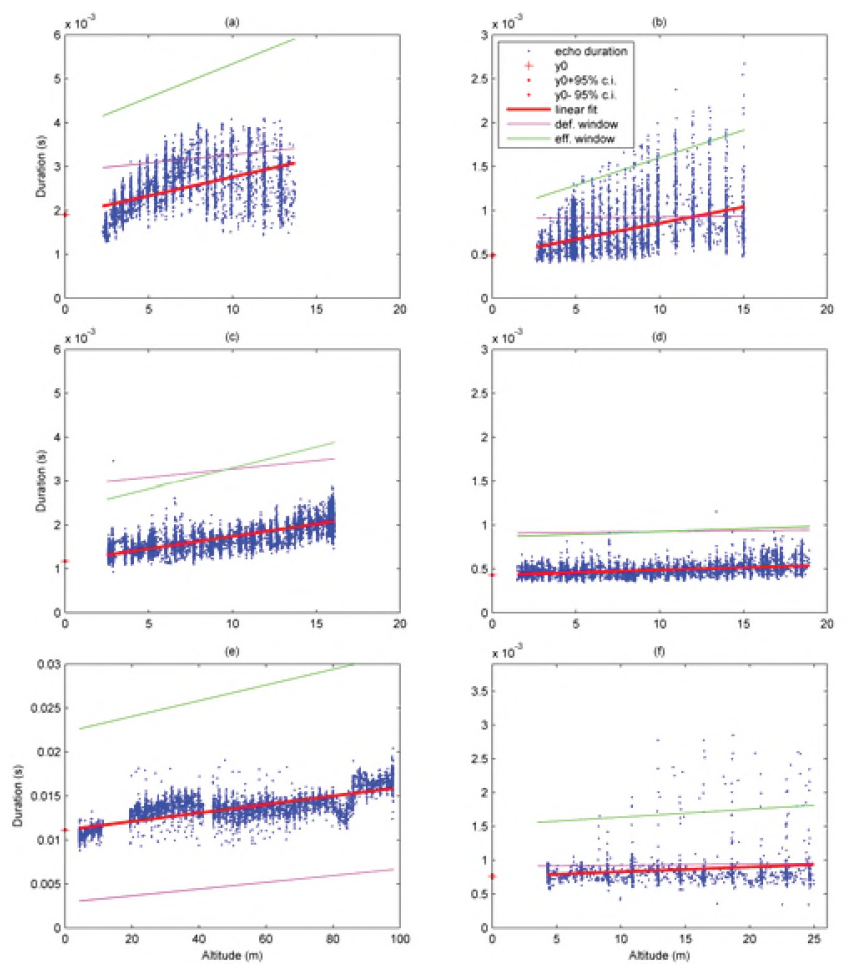

Figure 1. Measured echo duration plotted against the bottom pick of each echo, with linear regressions to 'depth'. The sediments are: gravel site at (a) $24 \mathrm{kHz}$, (b) $200 \mathrm{kHz}$; sand site at (c) $24 \mathrm{kHz}$, (d) $200 \mathrm{kHz}$; and mud site at (e) $24 \mathrm{kHz}$, (f) 200 $\mathrm{kHz}$. The red line and dots on the vertical axis indicate the yintercept and its error. The thick red lines are the regression lines. The magenta lines are the default analysis window, the green lines the analysis calculated from the effective

beamwidth and attenuation. The axes ratio is constant for each frequency.

\section{THE SLOPE EXPERIMENT}

Fig. 2 shows three new statistical measures of echo shape, called 'features', used for seabed classification (Bloomer et. al., 2010). Transducer tilt increases left to right simulating increasing seabed slope. In Fig. 2 (right) seabed slope is compensated for by inserting the tilt value into Eq.1 which is then used as if doing depth compensation as before. The result for the gravel site is dramatic. Virtually all of the slope effect is removed. However, this is only effective up to six to eight degrees for the sand and mud sites. This is because the high-roughness surficial backscattering that dominates the gravel site echoes is unaffected by slope, while processes that dominate the sand and mud site echoes are affected. In particular, the specular reflection is lost for slope greater than the $1 / 2$ beamwidth of 10 degrees. Also, measured echo durations increase with 'slope' as expected.
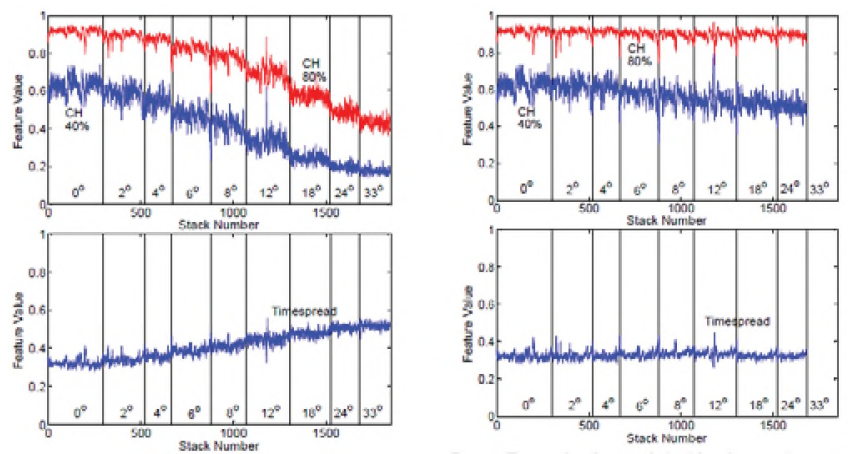

Figure 2. (top left) Two cumulative histogram features: $40 \%$ (blue) and $80 \%$ (red) versus increasing seabed slope (in steps). (lower left) The timespread feature. Both panes on the left were generated with normal depth compensation, while the panes on the right included the slope (ie tilt of the transducer) in Eq. 1 for combined depth and slope compensation. The vertical lines indicate the end of each pass of the $24 \mathrm{kHz}$ echosounder over the gravel site after which the tilt was increased in increments of 2 , up to 6 , degrees.

\section{DISCUSSION}

To our knowledge, echo duration data like these have never been published. Perhaps previous attempts failed because of a lack of a controlled testbed site. The setup for the depth experiment included 4-point anchoring and control of the transducer's attitude. Tail picking is also very difficult. The compensation of seabed slope using the echo duration model is a major improvement for single-beam classification.

Echo duration is a direct indicator of seabed type via seabed attenuation. The effective beamwidth also responds to the seabed type. However, this requires a homogenous seabed with some variation in depth. A method that provides such data in general survey conditions and combines the echo duration approach with other characterization methods will be published in the near future (Biffard, 2010).

\section{REFERENCES}

B. R. Biffard, J.M. Preston, and N.R. Chapman, "Acoustic classification with single-beam echosounders: processing methods and theory for isolating effects of the seabed on echoes," Proc. MTS/IEEE Oceans Conference, Vancouver, Canada, 2007.

B.R. Biffard, S.F. Bloomer, N.R. Chapman, J.M. Preston, and J.L. Galloway, "Single-beam seabed characterization: A test-bed for controlled experiments," Proc. Eighth European Conference on Underwater Acoustics, Carvoeiro, Portugal, 2006.

B.R. Biffard, Ph.D. thesis (in preparation), U. Victoria, 2010

S.F. Bloomer, X. Monteys and N.R. Chapman, "Multifrequency Classification and Characterization of Single Beam Echosounder data Collected from Offshore Ireland", in this proceedings, 2010 